\title{
Mechanisms of airway epithelial damage: epithelial-mesenchymal interactions in the pathogenesis of asthma
}

\author{
S.T. Holgate, D. E. Davies, S. Puddicombe, A. Richter, P. Lackie, J. Lordan, P. Howarth
}

\begin{abstract}
The aims of this article are to understand the shortfalls in thinking of asthma purely as an atopic disorder, to gain insight into the epithelial abnormalities of asthma and how these interface with the environment, and to view asthma as a disease of airway wall restructuring that engages activation of the epithelial mesenchymal trophic unit (EMTU). Furthermore, based on these developments, possible novel therapeutic targets for chronic asthma are identified.
\end{abstract}

\section{Mechanisms of airway epithelial damage}

It has long been recognised that T-helper cell (Th) type-2 airway inflammation underpins airway dysfunction in asthma. Atopy is also a key feature of this disease but accounts for $<40 \%$ of the population attributable risk. Based on a careful pathological and functional assessment of chronic asthma, the authors propose that altered epithelialmesenchymal communication is also fundamental to disease pathogenesis. A number of factors contribute to a thickened hyperresponsive airway that provides an ideal microenvironment for the persistence of Th2-mediated inflammation, including a more susceptible epithelium to injury, delayed epithelial repair, an altered trajectory of epithelial repair to a mucus-secreting phenotype, generation of growth factors that drive mesenchymal cell proliferation and differentiation towards increased matrix deposition and smooth muscle, and the production of neural and vascular growth factors. Cytokines and mediators derived from infiltrating inflammatory cells interact with this EMTU to augment and prolong responses. The "remodelling" changes of asthma have been observed in childhood asthma and may, indeed, precede the development of the disease. The recent recognition that atopy per se is not a key factor in the initiation of asthma (although it is important in aggravating the disease) suggests that geneenvironmental interactions involving similar processes to those occurring in branching morphogenesis are critical for the full asthma phenotype to develop.

\section{Introduction to asthma}

A recent National Institutes for Health Workshop and a European Respiratory Society Task Force both concluded that more work is needed to understand mechanisms of severe and chronic asthma [1, 2]. In isolation, Th2-mediated inflammation is insufficient to cause asthma, rather the asthmatic state results from a combination of the increased susceptibility

Correspondence: S.T. Holgate, Respiratory Cell and Molecular Biology, Division of Infection, Inflammation and Repair, Mailpoint 810, Level D, Centre Block, Southampton General Hospital, Southampton SO16 6YD, UK. Fax: 44 2380701771. E-mail: sth@ soton.ac.uk of the bronchial epithelium to injury and prolonged tissue repair involving an imbalance in responses to tyrosine kinase receptor ligands, such as epithelial growth factor (EGF) and transforming growth factor (TGF)- $\beta$, and Th2 cytokines. These alter cell-cell communication between the epithelium and underlying fibroblast sheath to cause activation of the EMTU, and in this way propagate and amplify structural changes in the airways creating a microenvironment for sustaining chronic inflammation.

\section{Asthma: a dynamic disorder of inflammation and remodelling}

Asthma is an inflammatory disorder of the airways involving T-cells, mast cells and eosinophils characteristic of a Th2-like response. However, inflammation alone does not explain many of the features of this chronic and relapsing disease. While atopy is an important risk factor for asthma, in the general population it accounts for $<40 \%$ of the attributable risk of having this disease [3]. Eosinophils have been assumed to play a central role in disease pathogenesis, however, the findings that an anti-interleukin (IL)-5-blocking monoclonal antibody [4] and recombinant human IL-12 [5] have no significant effect on allergen-induced early or latephase responses, despite markedly reducing circulating and airway eosinophil numbers, have raised a question over the primacy of this cell in asthma. Thus, while being associated with asthma, atopy and airway eosinophilia would not seem to be critical requirements for disease expression. Genetic studies have demonstrated that atopy and bronchial hyperresponsiveness (BHR) have different patterns of inheritance [6]. These findings imply that locally operating factors play an important role in predisposing individuals to asthma and provide an explanation for epidemiological evidence that identifies pollutant exposure [7], diet [8] and respiratory virus infection [9] that all increase oxidant stress in the airways.

Morphometry has revealed that thickening of asthmatic airways accounts for a large component of BHR and excessive airway narrowing observed in established asthma. In moderate/severe disease, the structural changes and BHR are poorly responsive to corticosteroids [10]. This failure of corticosteroids is reflected in the findings of the recent European Network for the Understanding of Severe Asthma study, which revealed that these patients exhibit a greatly impaired quality of life [11], a component of fixed airflow obstruction and have clear evidence of airway wall remodelling [12]. In such patients, evidence of persistent matrix turnover was found. Airway remodelling in adult asthma also provides an explanation for the accelerated decline in lung function observed over time [13]. The Childhood Asthma Management Program (CAMP) study in children aged 5-11 yrs has shown that the initial beneficial effect of an inhaled corticosteroid on the postbronchodilator improvement 
in airway function, observed during the first year of treatment, was lost over the following 3 yrs [14]. The more recent Inhaled Steroid Treatment as Regular Therapy in Early Asthma Study (START) study conducted on a very large population of newly diagnosed asthmatics clearly showed efficacy for inhaled budesonide on many asthma outcome measures, but again, a very limited or no effect on natural history as measured by the postbronchodilator forced expiratory volume in one second over 3 yrs [15]. This is best explained by airway remodelling that is insensitive to corticosteroids. A recent biopsy study identified tissue remodelling, as an early and consistent component of childhood asthma with fibroblast proliferation and collagen deposition in the subepithelial lamina reticularis, being of greater diagnostic significance than tissue eosinophilia [16]. Although remodelling has been considered to be secondary to long-standing inflammation, biopsy studies in young children have shown tissue restructuring up to 4 yrs before the onset of symptoms [17], indicating processes that begin early in the development of asthma and occur in parallel with, or may be obligatory for, the establishment of persistent inflammation.

\section{Epithelial susceptibility to injury and the repair phenotype in asthma}

The normal bronchial epithelium is a stratified structure consisting of a columnar layer supported by basal cells to serve as a physical and chemical barrier to the external environment. In asthma, the epithelium shows ample evidence of injury and activation as well as goblet cell metaplasia. Epithelial stress is seen in the form of widespread activation of nuclear transcription factor- $\kappa \mathrm{B}[18,19]$, activator proteins (e.g. activator protein-1) [20] and signal transducer and activation of transcription (STAT)-1 [21], and by the increased expression of heat shock proteins [22] and the cyclindependent kinase inhibitor, p21 ${ }^{\text {waf }}$ [23]. The altered epithelium also becomes an important source of autacoid mediators, chemokines and growth factors [24] that sustain ongoing inflammation.

\section{Epithelial susceptibility}

While epithelial disruption is reportedly increased in the asthmatic bronchial epithelium, it has been proposed that this is artefactual [25]. However, findings of enhanced expression of the epidermal growth factor receptor (EGFR) [26] and the epithelial isoform of CD44 [27] indicate that injury has occurred in vivo. EGFR and CD44 expression in asthma increase in proportion to disease severity, and this is evident throughout the epithelium suggesting that damage is widespread [26, 27]. EGFR overexpression is also insensitive to the action of corticosteroids and is positively correlated with the thickness of the lamina reticularis [26], which provides a basis for linking epithelial injury to an underlying remodelling response. The extent of epithelial shedding in asthma is not observed in other inflammatory diseases such as chronic obstructive pulmonary disease (COPD). In COPD the epithelium becomes multilayered and undergoes squamous metaplasia while the underlying lamina reticularis remains normal. While it is possible that these differences reflect the type of inflammation present, airway eosinophilia is observed in the absence of asthma [28] and neutrophils may dominate inflammation in severe asthma, as in COPD [12].

In bronchial biopsies, markedly increased immunostaining of asthmatic columnar (but notably not basal) epithelial cells for $\mathrm{p} 85$, the caspase- 3 cleavage product of poly(adenosine diphosphate-ribose) polymerase is seen, indicating that epithelial apoptosis is increased in this disease [29]. While these histological studies identify epithelial differences between asthmatic and normal subjects, they are unable to differentiate whether the changes are a cause or a consequence of inflammation. To address this, the authors established primary cultures using bronchial epithelial cells brushed from the airways of normal and asthmatic subjects in order to compare responses under identical conditions in vitro. Although under optimal growth conditions no difference in the rate of proliferation of these cultures have been found, when rendered quiescent by growth factor depletion, those cells from asthmatic airways exhibit a significantly greater sensitivity to oxidant-induced apoptosis in the face of a normal apoptotic response to the deoxyribonucleic acid (DNA) and ribonucleic acid synthesis inhibitor, actinomycin D [29]. This susceptibility to oxidants is unlikely to be a secondary effect of airway inflammation as it is preserved through several generations in vitro. Since epidemiological studies [30, 31] have identified multiple interacting risk factors for asthma, including inhalant pollutants and diets low in antioxidants, the present authors propose that the effect of environmental oxidants on a susceptible epithelium provides a plausible triggering mechanism for the induction of epithelial activation and damage in asthma. Once initiated, the resulting inflammatory cell influx causes secondary damage through production of endogenous reactive oxygen species resulting in chronic tissue injury and persistent inflammation.

It was recently shown that epithelial expression of the neutrophil chemoattractants IL-8 and macrophage inflammatory protein (MIP)- $1 \alpha$ is increased in severe asthma, and that their appearance correlates with increased EGFR expression as a marker of epithelial damage. Further in vitro studies have revealed that oxidant or EGF treatment of primary bronchial epithelial cells enhances MIP- $1 \alpha$ or IL-8 release, respectively [32]. Thus, beyond mild intermittent disease that is strongly linked to atopy, the susceptibility of the epithelial barrier to the action of different components of the inhaled environment plays a key role in determining the asthmatic phenotype.

\section{Growth arrest and epithelial repair}

In vitro studies point to a central role for activation of the EGFR in the restoration of the bronchial epithelium following injury, since EGF is a mitogen for bronchial epithelial cells [23], mechanical damage induces rapid phosphorylation of the EGFR irrespective of the presence of exogenous ligand [26], and wound closure is enhanced by EGF but not by the unrelated ligand keratinocyte growth factor [26]. Although EGF is a potent mitogen, the increase in epithelial EGFR in asthma is not matched by increased proliferation to replace columnar cells that have been lost as a result of caspase cleavage of intercellular adhesion molecules $[23,33]$. This contrasts with the hyperproliferative state of the epithelium seen in COPD. Although studies with primary cultures of normal and asthmatic bronchial epithelial cells have shown similar proliferation rates when maintained in medium supplemented with exogenous EGF [29], the authors have found a potential mechanism for reduced EGFRmediated proliferation in vivo, regarding the cyclin-dependent kinase inhibitor, p $21^{\text {waf }}$ that is overexpressed in basal as well as columnar epithelial cells in bronchial biopsies from patients with severe asthma [23]. While in mild asthma p $21^{\text {waf }}$ at a cytoplasmic location protects the columnar cells from oxidant injury, in more severe disease it is expressed in 
basal cells at a nuclear location where it serves as a checkpoint at the G1 to S-phase transition of the cell cycle causing growth arrest. This enables DNA repair to be completed before progression into S-phase or, where damage is irreparable, to direct exit from the cell cycle and activate apoptosis. In this way, the decision to survive or to enter into apoptosis are linked. The EGFR ligands are determinants of epithelial cell fate through their ability to act as survival factors [34] that protect against proapoptotic stimuli and as mitogens that signal cell cycle progression. Although the ability of EGF to protect against oxidant-induced apoptosis in vitro has not yet been characterised, studies in animal models have shown that EGF can protect against smokeinduced tracheal injury in sheep [35].

As expression of $\mathrm{p} 21^{\text {waf }}$ is strongly induced by oxidant stress [25], the finding that asthmatic bronchial epithelial cells are more susceptible to oxidant injury provides one explanation for its high expression in asthmatic epithelium. However, p2 ${ }^{\text {waf }}$ is also induced by the antiproliferative growth factors TGF- $\beta_{1}$ and TGF- $\beta_{2}$ whose levels are elevated in asthma, in COPD [36] and in response to epithelial injury in vitro [26, 37]. Since mitogen-activated protein kinase (MAPK) activation by mitogens such as EGF antagonises TGF- $\beta$ signalling [38], the overall fate of the epithelium will reflect integration of survival and proliferation signals provided by EGF-like growth factors and the counterbalancing effect of proapoptotic and antiproliferative signals caused by injury and members of the TGF- $\beta$ family, including the bone morphogenic proteins. Although expression of EGFR ligands [39] are unchanged in asthmatic bronchial epithelium relative to normal controls, in COPD there is markedly increased TGF- $\alpha$ production. Thus, in COPD increased activation of the EGFR by EGF and analogous ligands protects against cigarette smoke-induced injury and overrides the antiproliferative effect of TGF- $\beta$, whereas in asthma an insufficiency of these ligands provides a unifying mechanism for increased epithelial susceptibility and impaired repair. This is supported by the finding of a marked decrease in epithelial immunostaining for phosphotyrosine (a global marker of tyrosine kinase activation) in the bronchial epithelium in mild asthma [40] and the reported lack of MAPK activation [41]. In contrast, in severe corticosteroid-requiring asthma, tyrosine kinase activity is markedly increased in relation to disease severity [40].

In asthma, while the EGFR, c-erbB1, is markedly overexpressed there is no increase in epithelial expression of the related EGFRs, HER-2 (c-erbB2) or HER-3 (c-erbB3) [40], whereas in COPD both of these receptors are overexpressed in parallel with the EGFR (unpublished observations). As EGFR:EGFR homodimers are only weak activators of the MAPK pathway [42], this will further contribute to the inability of the asthmatic epithelium to counter antiproliferative signals provided by TGF- $\beta$. In contrast, EGFR:HER2 heterodimers are potent signal transducers [43] and will augment epithelial proliferation in COPD, while c-erbB3-containing heterodimers are able to promote cell survival due to the presence of multiple binding sites for phosphatidyl inositol 3-kinase on this receptor [44] and related signalling substrate for SMAD signalling receptors. Thus, the duration of epithelial repair is prolonged in asthma due to an imbalance between proliferation and survival signals involving the EGFR/HER family and antiproliferative signals involving TGF- $\beta$.

\section{The epithelial mesenchymal trophic unit}

High-resolution computed tomography, post mortem and biopsy studies in chronic asthma have all revealed airway wall thickening. This involves deposition of interstitial collagens in the lamina reticularis [45], matrix deposition in the submucosa, smooth muscle hyperplasia, and microvascular and neuronal proliferation. Thickening of the lamina reticularis is diagnostic of this disease and, on the basis of measurements made in human airways [46] and in a guinea-pig model of chronic antigen exposure [47, 48], it appears to reflect events linked to thickening of the entire airway wall [49]. In 1990, a layer of subepithelial mesenchymal cells with features of myofibroblasts were described, whose number was increased in asthma in proportion to the thickness of the reticular collagen layer [50]. In location and function these cells correspond to the attenuated fibroblast sheath described by EvAns et al. [51] lying adjacent to the lamina reticularis and forming a network similar to hepatic stellate cells which, when activated by liver damage, are the key effector cells responsible for fibrosis [52]. As the bronchial epithelium is in contact with the attenuated fibroblast sheath, these two cellular layers are in a key position to coordinate responses to challenges from the inhaled environment into the deeper layers of the submucosa [53].

Injury to epithelial monolayers in vitro results in increased release of fibroproliferative and fibrogenic growth factors including fibroblast growth factor (FGF)-2, insulin-like growth factor (IGF)-1, platelet-derived growth factor (PDGF), endothelin (ET)-1 and latent and active TGF- $\beta_{2}[37,54]$. The authors have also found that TGF- $\beta$, FGF-2 and ET- 1 are increased in asthma [55-57] with TGF- $\beta$ and FGF-2 being encrypted in the extracellular matrix as shown by their colocalisation with the proteoglycans decorin and heparan sulphate, respectively [58]. To further establish the relationship between EGFR signalling in the repair and remodelling processes, the authors have used an EGFR-selective tyrosine kinase inhibitor that suppresses epithelial repair in vitro with a resultant increase in release of TGF- $\beta_{2}$ from the damaged epithelial cells [26]. This points to parallel pathways operating in repairing epithelial cells, some of which direct restitution and are regulated by the EGFR, while others control profibrogenic growth factor production independent of the EGFR. In asthma, it is suggested that impaired epithelial proliferation causes the bronchial epithelium to spend longer in a repair phenotype resulting in increased secretion of profibrogenic growth factors.

Using a co-culture model, there is evidence that epithelial injury causes myofibroblast activation. Polyarginine (a surrogate for eosinophil basic proteins), mechanical damage or distortion of confluent monolayers of epithelial cells grown on a collagen gel seeded with human lung myofibroblasts leads to enhanced proliferation and increased collagen gene expression due to the combined effects of FGF-2, IGF-1, PDGF-BB, TGF- $\beta$ and ET-1 [37]. In moderate asthma, inhaled corticosteroids reduce airway inflammation and levels of IGF-1 and FGF-2, but with limited improvement in BHR and only partial effects on collagen deposition in the lamina reticularis and TGF- $\beta$ levels [59].

As corticosteroids reduced submucosal eosinophils by $\sim 80 \%$, the persistently high TGF- $\beta$ in bronchoalveolar lavage (BAL) fluid most likely derives from the injured and repairing epithelium and associated matrix turnover in addition to eosinophils. Since both epithelial EGFR expression [26] and TGF- $\beta$ production are refractory to corticosteroids, the combined effects of these signalling pathways on the EMTU could provide mechanisms for tissue remodelling and explains the incomplete resolution of lung function with inhaled corticosteroids observed in chronic asthma.

Communication between the epithelium and the subepithelial fibroblast sheath is reminiscent of the processes that drive physiological remodelling of the airways during embryogenesis where the epithelium and mesenchyme act as a "trophic 
unit" to regulate airway growth and branching [60]. Consequently, the authors propose that the EMTU is reactivated in asthma to drive pathological remodelling of the airways [53]. In subjects with asymptomatic BHR, longitudinal studies have shown that those who progress to asthma show parallel changes in inflammation and remodelling [61]. Thickening of the lamina reticularis in bronchial biopsies from young children is also present several years before asthma becomes clinically manifest [17]. During lung development, epithelial and mesenchymal growth is in part regulated by the balance of EGF and TGF- $\beta$ signalling, as suggested to occur in chronic asthma. In susceptible individuals, it is proposed that environmental factors interact with the EMTU in early life to initiate structural changes in the airways that may account for the decrease in lung function observed in young children who are susceptible to early wheezing [62] and for the loss of corticosteroid responsiveness on baseline lung function observed in the CAMP and START studies [14, 15]. This is supported by very recent studies in nonhuman primates where intermittent exposure to ozone in the presence of allergen creates a phenotype resembling chronic asthma [31]. Therefore, bronchial epithelial susceptibility seems to either precede or occur in parallel with factors predisposing to Th2-mediated inflammation and is a requirement to establish the microenvironment for inflammation to become persistent in the airways and for remodelling to occur.

\section{Propagation of remodelling responses by the epithelial mesenchymal trophic unit}

To study the mesenchymal cells that are involved in the remodelling responses in asthma, protocols for their outgrowth from bronchial biopsies have been established. These fibroblasts can be grown readily from asthmatic mucosal biopsies and differ from those from normal airways in adopting stem cell characteristics by proliferating rapidly in the absence of exogenous growth factors and by their ability to overcome contact inhibition in the presence of TGF- $\beta_{1}$ or TGF- $\beta_{2}$ enabling higher cell densities to be achieved [63]. In this regard, TGF- $\beta_{1}$ treatment in vitro also causes submucosal fibroblasts to adopt a myofibroblast phenotype as evidenced by induction of $\alpha$-smooth muscle actin ( $\alpha$-SMA), acquisition of a contractile phenotype and synthesis of interstitial (repair) collagens. Although the relationship between myofibroblast activation and the underlying smooth muscle mass in asthma has yet to be studied, following allergen exposure an increase in BAL fluid of the smooth muscle and vascular mitogen, ET1 was found [57], and TGF- $\beta$ treatment of asthmatic mucosal fibroblasts in vitro caused them to release both ET-1 and another vascular mitogen, vascular endothelial growth factor (VEGF) [63]. TGF- $\beta$ results in greatly enhanced production of connective tissue growth factor and it is this that probably drives most of the new matrix production. In addition to increased matrix deposition, activation of myofibroblasts contributes to smooth muscle and microvascular proliferation, which are both characteristic features of the remodelled asthmatic airway [64].

In a rabbit model of partial outflow obstruction in the bladder, TGF- $\beta$ causes serosal thickening due to accumulation of myofibroblasts, which, over time, change phenotype into smooth muscle cells [65]. In developing capillaries, endothelial cells and smooth muscle cells also share a common stem cell progenitor with VEGF and PDGF acting as the key determinants of cell fate [66]. The authors' studies of normal and asthmatic airway (myo)fibroblasts reveal that these cells exhibit phenotypic plasticity, have some early features of smooth muscle e.g. expression of the SM-22 protein, and can be further differentiated by TGF- $\beta_{1}$ and TGF- $\beta_{2}$ to express heavy chain myosin and $\alpha$-SMA [63, 67]. This suggests that the cells have properties of both myofibroblasts and smooth muscle cells and are probably derived from a common progenitor. Thus, mediators released by the repairing bronchial epithelium provide a mechanism for myofibroblast activation to propagate and amplify airway remodelling. Such a mechanism would fit well with the recent findings on airway smooth muscle cultured from asthmatic airways [64].

\section{The interaction between interleukin- 4 and -13 and the epithelial mesenchymal trophic unit}

Th2-type inflammation of the airways is a characteristic feature of asthma, irrespective of atopy. In view of transgenic mice studies that have suggested that expression of an IL-13 (but not IL-4) transgene in the bronchial epithelium leads to submucosal remodelling [68, 69], the role of IL-4 and IL-13 in asthmatic epithelial cell and fibroblast function was investigated. The expression of the high affinity IL-13R $\alpha_{2}$ chain is restricted to airway epithelial cells and fibroblasts and is coexpressed with IL-13R $\alpha_{1}$ and IL-4R $\alpha$ [70]. Both IL-4 and IL-13 signal via the transcription factor STAT-6 [71] whose expression has been shown to be prominent in the bronchial epithelium and further increased in severe asthma [72]. While it has been shown that IL-13 is able to induce myofibroblast transformation, it is less potent than TGF- $\beta$ and equipotent with IL-4 [63]. Since parallel experiments revealed that IL-13 causes a corticosteroid-insensitive increase in release of TGF$\beta_{2}$ from bronchial epithelial cells, it seems likely that IL-13mediated submucosal remodelling is initiated largely through the bronchial epithelium [63]. A recent report from ZHU et al. [73] supports this conclusion as both fibrosis and smooth muscle hyperplasia in the airways of mice expressing a bronchial epithelial-specific IL-13 transgene is TGF- $\beta$-dependent. However, in human epithelial cells, IL-4 is as effective as IL-13 in promoting TGF- $\beta$ release, raising the possibility of an important species difference in epithelial IL-4 and IL-13 receptor expression.

While the remodelling effects of IL-4 and IL-13 can be attributed to epithelial activation, these cytokines also have direct proinflammatory effects on both epithelial cells and fibroblasts. Cultures of bronchial epithelial cells respond to IL-4 and IL-13 with increased STAT-6 phosphorylation accompanied by enhanced granulocyte/macrophage colonystimulating factor and IL-8 production which is further augmented by enzymatically active extracts of house dust mite (Dermatophagoides pteronyssinus, Der p) [72, 74]. Enhanced release of eotaxin from asthmatic fibroblasts [63] has also been found, which may help explain the accumulation of eosinophils beneath the lamina reticularis in asthma. Thus, by interacting with the EMTU, IL-4 and IL-13 contribute to chronic inflammation and airway remodelling.

\section{Conclusion}

The T-helper cell type- 2 paradigm of asthma has explained the link of atopy to this disease but has not provided a good explanation for disease chronicity and severity. To take account of this, the authors propose that a second series of events are needed whereby the airways behave like a chronic wound with production of growth factors active on mesenchymal cells. This activation of the epithelial mesenchymal trophic unit provides a necessary stimulus for altered airway wall structure and function and may explain the decline in 
lung function observed over time in this disease as well as the corticosteroid refractory component of BHR. This new way of thinking about chronic asthma provides the basis for developing new therapeutic strategies for tackling the residual unmet clinical need, as shown recently for the beneficial effects of human recombinant epithelial growth factor in ulcerative collitis, another chronic inflammatory disorder involving the epithlium [75].

\section{References}

1. Banks-Schlegel S, Busse WW, Wenzel SE. Report on the NIH NHLBI's Workshop on the pathophysiology of severe asthma. J Allergy Clin Immunol 2000; 106: 1033-1042.

2. Chung KF, Godard P. Difficult therapy resistant asthma: An ERS Task Force Report. Eur Respir Rev 2000; 10: 1-101.

3. Pearce N, Pekkanen J, Beasley R. How much asthma is really attributable to atopy? Thorax 1999; 54: 268-272.

4. Leckie MJ, Brinke AT, Khan J, et al. Effects of an interleukin-5 blocking monoclonal antibody on eosinophils, airways hyper responsiveness, and the late asthmatic response. Lancet 2000; 356: 2144-2148.

5. Bryan SA, Kanabar V, Matti S, et al. Effect of recombinant human interleukin-12 on eosinophils, airway hyperresponsiveness and the late asthmatic response. Lancet 2000; 356: 2149-2153.

6. Skadhuage LR, Christensen K, Kyvik KO, Sigsgaard T. Genetic and environmental influence on asthma: a population based study of 11,688 Danish twin pairs. Eur Respir $J$ 1999; 13: 8-14.

7. Rahman I, MacNee W. Oxidative stress and regulation of glutathione in lung inflammation. Eur Respir J 2000; 16: 534-554.

8. Holgate ST. Genetic and environmental interaction in allergy and asthma. J Allergy Clin Immunol 1999; 104: 1139-1146.

9. Papi A, Johnston SL. Rhinovirus infection induces expression of its own receptor intercellular adhesion molecule 1 (ICAM-1) via increased NF-kappaB-mediated transcription. J Biol Chem 1999; 274: 9707-9720.

10. Reddel HK, Jenkins CR, Marks GB, et al. Optimal asthma control, starting with high doses of inhaled budesonide. Eur Respir J 2000; 16: 226-235.

11. European Network for the Understanding of Severe Asthma (ENFUMOSA) Study Group. Quality of life in severe asthma. Am J Respir Crit Care Med 2000; 161: A923.

12. European Network for the Understanding of Severe Asthma (ENFUMOSA) Study Group. The ENFUMOSA crosssectional European multicentre study of the clinical phenotype of chronic severe asthma. Eur Respir J 2003; (In press).

13. Lange P, Parner J, Vestbo J, Schnohr P, Jensen G. A 15-year follow-up study of ventilatory function in adults with asthma. N Engl J Med 1998; 339: 1194-1200.

14. The Childhood Asthma Management Program Research Group. Long-term effects of budesonide or nedocromil in children with asthma. N Engl J Med 2000; 343: 1054-1063.

15. Pauwels RA, Pederson S, Busse WW, et al. Early intervention with budesonide in mild persistent asthma: a randomised, double-blind trial. Lancet 2003; 361: 1071-1076.

16. Cokugras H, Akcakaya N, Seckin I, Camcioglu Y, Sarimurat N, Aksoy F. Ultrastructural examination of bronchial biopsy specimens from children with moderate asthma. Thorax 2001; 56: 25-29.

17. Pohunek P, Roche WR, Tarzikova J, Kurdman J, Warner JO. Eosinophilic inflammation in the bronchial mucosa of children with bronchial asthma. Eur Respir J 1997; 10: Suppl. 25,160 s.

18. Hart LA, Krishnan VL, Adcock IM, Barnes PJ, Chung KF. Activation and localization of transcription factor, nuclear factor-kappaB, in asthma. Am J Respir Crit Care Med 1998; 158: $1585-1592$.
19. Wilson SJ, Leone BA, Anderson D, Manning A, Holgate ST Immunohistochemical analysis of the activation of NF- $\kappa \mathrm{B}$ and expression of associated cytokines and adhesion molecules in human models of allergic inflammation. J Pathol 1999; 189: 265-272.

20. Demoly P, Basset-Seguin N, Chanez P, et al. c-fos protooncogene expression in bronchial biopsies of asthmatics. Am J Respir Cell Mol Biol 1992; 7: 128-133.

21. Sampath D, Castro M, Look DC, Holtzman MJ. Constitutive activation of an epithelial signal transducer and activator of transcription (STAT) pathway in asthma. $J$ Clin lnvest 1999; 103: 1353-1361.

22. Bertorelli G, Bocchino V, Zhuo X, et al. Heat shock protein 70 upregulation is related to HLA-DR expression in bronchial asthma. Effects of inhaled glucocorticoids. Clin Exp Allergy 1998; 28: 551-560.

23. Puddicombe SM, Torres-Lozano C, Richter A, et al. Increased expression of $\mathrm{p} 21$ (waf) cyclin-dependent kinase inhibitor in asthmatic bronchial epithelium. Am J Respir Cell Mol Biol 2003; 28: 61-68.

24. Chung KF, Barnes PJ. Cytokines in asthma. Thorax 1999; 54: 825-857.

25. Ordonez C, Ferrando R, Hyde DM, Wang HH, Fahy JV. Epithelial desquamation in asthma. Artifact or pathology? Am J Respir Crit Care Med 2000; 162: 2324-2329.

26. Puddicombe SM, Polosa R, Richter A, et al. The involvement of the epidermal growth factor receptor in epithelial repair in asthma. FASEB $J$ 2000; 14: 1362-1374.

27. Lackie PM, Baker JE, Gunthert D, Holgate ST. Expression of CD44 isoforms is increased in the airway epithelium of asthmatic subjects. Am J Respir Cell Mol Biol 1997; 16: 14 22.

28. Ward PA, Gibson PG, Fakes K. Induced sputum eosinophils in the assessment of asthma and chronic cough. Respirology 2000; 5: 51-57.

29. Bucchieri F, Puddicombe SM, Lordan JL, et al. Asthmatic bronchial epithelium is more susceptible to oxidant-induced apoptosis. Am J Respir Cell Mol Biol 2002; 27: 179-185.

30. Nel AE, Diaz-Sanchez D, Li N. The role of particulate pollutants in pulmonary inflammation and asthma: evidence for the involvement of organic chemicals and oxidative stress. Curr Opin Pulm Med 2001; 7: 20-26.

31. Miller LA, Hyde DM, Gershwin LJ, et al. The effect of house dust mite aeroallergen and air pollutant exposure during infancy. Chest 2003; 123: Suppl. 3, 434s.

32. Hamilton LM, Torres-Lozano C, Puddicombe SM, et al. The role of the epidermal growth factor receptor in sustaining neutrophil inflammation in severe asthma. Clin Exp Allergy 2003; 33: 233-240.

33. Demoly $\mathrm{P}$, Simony-Lafontaine J, Chanez $\mathrm{P}$, et al. Cell proliferation in the bronchial mucosa of asthmatics and chronic bronchitics. Am J Respir Crit Care Med 1994; 150: 214-217.

34. Jost M, Kari C, Rodeck U. The EGF receptor - an essential regulator of multiple epidermal functions. Eur J Dermatol 2000; 10: 505-510.

35. Barrow RE, Wang CZ, Evans MJ, Herndon DN. Growth factors accelerate epithelial repair in sheep trachea. Lung 1993; 171: 335-344.

36. Vignola AM, Chanez P, Chiappara G, et al. Transforming growth factor-beta expression in mucosal biopsies in asthma and chronic bronchitis. Am J Respir Crit Care Med 1997; 156: 591-599.

37. Zhang S, Smartt H, Holgate ST, Roche WR. Growth factors secreted by bronchial epithelial cells control myofibroblast proliferation: an in vitro co-culture model of airway remodeling in asthma. Lab Invest 1999; 79: 395-405.

38. Kretzschmar M, Doody J, Massague J. Opposing BMP and EGF signalling pathways converge on the TGF-beta family mediator Smad1. Nature 1997; 389: 618-622.

39. Polosa R, Puddicombe SM, Krishna MT, et al. Expression of c-erbB receptors and ligands in the bronchial epithelium 
of asthmatic subjects. J Allergy Clin Immunol 2002; 109: 7581.

40. Hamilton LM, Kimber I, Dearman RJ, et al. Protein tyrosine phosphorylation in normal and asthmatic bronchial epithelium. Immunology 2000; 101: Suppl. 1, 82.

41. Koch A, Ito K, Tomita K, et al. Phosphorylation of mitogen activated protein kinases $\mathrm{p} 44^{\mathrm{ERK} 1}$ and $\mathrm{p} 42^{\mathrm{ERK} 2}$ in bronchial biopsies from asthmatic and normal subjects - Effect of theophylline. Am J Respir Crit Care Med 2000; 161: A742.

42. Lenferink AE, Pinkas-Kramarski R, van de Poll ML, et al. Differential endocytic routing of homo- and hetero-dimeric ErbB tyrosine kinases confers signaling superiority to receptor heterodimers. EMBO J 1998; 17: 3385-3397.

43. Graus-Porta D, Beerli RR, Daly JM, Hynes NE. ErbB-2, the preferred heterodimerization partner of aIl ErbB receptors, is a mediator of lateral signaling. EMBO J 1997; 16: 16471655.

44. Fedi P, Pierce JH, di Fiore PP, Kraus MH. Efficient coupling with phosphatidylinositol 3-kinase, but not phospholipase C gamma or GTPase-activating protein, distinguishes ErbB-3 signaling from that of other ErbB/EGFR family members. Mol Cell Biol 1994; 14: 492-500.

45. Roche WR, Beasley R, Williams JH, Holgate ST. Subepithelial fibrosis in the bronchi of asthmatics. Lancet 1989; i: 520-524

46. Boulet LP, Laviolette M, Turcotte $\mathrm{H}$, et al. Bronchial subepithelial fibrosis correlates with airway responsiveness to methacholine. Chest 1997; 112: 45-52.

47. Toda M, Yoshida M, Nakano Y, Cheng G, Motojima S, Fukada T. An animal model for airway wall thickening. J Allergy Clin lmmunol 1997; 99: S409.

48. Toda M, Yoshida M, Nakano Y, Cheng G, Motojima S, Fukada T. Basal lamina thickening in airway wall of an animal model. J Allergy Clin Immunol 1998; 101: S149.

49. Chetta A, Foresi A, Del Donno M, Bertorelli G, Pesci A, Olivieri D. Airways remodeling is a distinctive feature of asthma and is related to severity of disease. Chest $1997 ; 111$ : 852-857.

50. Brewster CE, Howarth PH, Djukanovic R, Wilson J, Holgate ST, Roche WR. Myofibroblasts and subepithelial fibrosis in bronchial asthma. Am J Respir Cell Mol Biol 1990; 3: $507-511$.

51. Evans MJ, van Winkle LS, Fanucchi MV, Plopper CG. The attenuated fibroblast sheath of the respiratory tract epithelial-mesenchymal trophic unit. Am J Respir Cell Mol Biol 2000; 21: 655-657.

52. Arthur MJ, Mann DA, Iredale JP. Tissue inhibitors of metalloproteinases, hepatic stellate cells and liver fibrosis. J Gastroenterol Hepatol 1998; 13: Suppl. 13, S33-S38.

53. Holgate ST, Davies DE, Lackie PM, Wilson SI, Puddicombe SM, Lordan JL. Epithelial-mesenchymal interactions in the pathogenesis of asthma. J Allergy Clin Immunol 2000; 105: 193-204.

54. Howat WH, Holgate ST, Lackie PM. TGF-beta isoform release and activation during in vitro bronchial epithelial wound repair. Am J Physiol Lung Cell Mol Physiol 2002; 282: L15-L23.

55. Redington AE, Madden J, Frew AJ, et al. Transforming growth factor-beta 1 in asthma. Measurement in bronchoalveolar lavage fluid. Am J Respir Crit Care Med 1997; 156: 642-647.

56. Redington AE, Roche WR, Madden J, et al. Basic fibroblast growth factor in asthma: measurement in bronchoalveolar lavage fluid basally and following allergen challenge. J Allergy Clin Immunol 2001; 107: 384-387.

57. Makker HK, Springall DR, Redington AE, et al. Airway endothelin levels in asthma: influence of endobronchial hypertonic saline challenge. Clin Exp Allergy 1999; 29: 241-247.

58. Redington AE, Roche WR, Holgate ST, Howarth PH. Co-localization of immunoreactive transforming growth factor-beta 1 and decorin in bronchial biopsies from asthmatic and normal subjects. $J$ Pathol 1998; 186: 410-415.

59. Hoshino M, Nakamura Y, Sim JJ, et al. Inhaled corticosteroid reduced lamina reticularis of the basement membrane by modulation of insulin-like growth factor (IGF)-1 expression in bronchial asthma. Clin Exp Allergy 1998; 28: 568577.

60. Warburton D, Schwarz M, Tefft D, Flores-Delgado G, Anderson KD, Cardoso WV. The molecular basis of lung morphogenesis. Mech Dev 2000; 92: 55-81.

61. Laprise C, Laviolette M, Boutet M, Boulet LP. Asymptomatic airway hyperresponsiveness: relationships with airway inflammation and remodelling. Eur Respir J 1999; 14: 63-73.

62. Stick S. The contribution of airway development to paediatric and adult lung disease. Thorax 2000; 55: 587-594.

63. Richter A, Puddicombe SM, Lordan J, et al. The contribution of interleukin-4 and interleukin-13 to the epithelialmesenchymal trophic unit in asthma. Am J Respir Cell Mol Biol 2001; 25: 385-391.

64. Johnson PR, Roth M, Tamm M, et al. Airway smooth muscle cell proliferation is increased in asthma. Am J Respir Crit Care Med 2001; 164: 474477.

65. Roelofs M, Faggian L, Pampinella F, et al. Transforming growth factor betal involvement in the conversion of fibroblasts to smooth muscle cells in the rabbit bladder serosa. Histochem J 1998; 30: 393-404.

66. Yamashita J, Itoh $\mathrm{H}$, Hirashima M, et al. Flk1-positive cells derived from embryonic stem cells serve as vascular progenitors. Nature 2000; 408: 92-96.

67. Chaudhary N, Richter A, Collins JE, Roche WR, Davies DE, Holgate ST. Phenotype comparison of asthmatic and nonasthmatic (myo)fibroblasts. Am J Respir Crit Care Med 2001; 163: A473.

68. Zhu Z, Homer RJ, Wang Z, et al. Pulmonary expression of interleukin-13 causes inflammation, mucus hypersecretion, subepithelial fibrosis, physiologic abnormalities, and eotaxin production. J Clin Invest 1999; 103: 779-788.

69. Rankin JA, Picarella DE, Geba GP, et al. Phenotypic and physiologic characterization of transgenic mice expressing interleukin 4 in the lung: lymphocytic and eosinophilic inflammation without airway hyperreactivity. Proc Natl Acad Sci USA 1996; 93: 7821-7825.

70. Konstantinidis AK, Lordan JL, Bucchieri F, et al. IL-13 receptor $\alpha 2$ expression by human bronchial epithelium. Am J Respir Crit Care Med 2001; 163: A737.

71. Nelms K, Huang H, Ryan J, Keegan A, Paul WE. Interleukin-4 receptor signalling mechanisms and their biological significance. Adv Exp Med Biol 1998; 452: 37-43.

72. Mullings RE, Wilson SI, Djukanovic R, et al. Increased STAT6 expression in bronchial epithelium of severe asthmatic subjects. J Allergy Clin Immunol 2001; 108: 832-838.

73. Zhu Z, Ma B, Zheng T, et al. IL-13-induced chemokine responses in the lung: role of CCR2 in the pathogenesis of IL-13-induced inflammation and remodeling. J Immunol 2002; 168: 2953-2962.

74. Lordan JL, Bucchieri F, Richter A, et al. Co-operative effects of Th-2 cytokines and allergen on normal and asthmatic bronchial epithelial cells. J Immunol 2002; 169: 407-414.

75. Sinha A, Nightingale JMP, West KP, Berlanga-Acosta J, Playford RJ. Epidermal growth factor enemas with oral mesalamine for mild-to-moderate left-sided ulcerative colitis or proctitis. N Engl J Med 2003; 349: 350-357. 